\title{
Effects of presentation rate and individual differences in short-term memory capacity on an indirect measure of serial learning
}

\author{
PETER A. FRENSCH and CAROLINE S. MINER \\ University of Missouri, Columbia, Missouri
}

\begin{abstract}
In three experiments, we studied the relation between degree of implicit learning and two aspects of short-term memory: (1) the activation level of the to-be-learned information, and (2) individual differences in short-term memory capacity. In all the experiments, we used the Nissen and Bullemer (1987) serial reaction time paradigm or a modification thereof. The effects of activation level were assessed by experimentally manipulating the rate of presentation. Individual differences in short-term memory capacity were assessed via traditional span measures. The experiments demonstrated that the rate of presentation reliably affected an indirect measure of learning (i.e., response time) under both incidental and intentional task instructions and under both single-task and dual-task conditions. Short-term memory span was reliably related to the indirect measure of learning only in some experimental conditions. The findings represent important constraints for models of implicit serial learning and are discussed within a general framework for understanding implicit learning and memory.
\end{abstract}

Serial learning is typically governed by the explicit intention to learn, as is perhaps most obvious in children's attempts to acquire the algorithms underlying mental arithmetic. Nevertheless, it appears that a good deal of serial learning is incidental and unintentional. For example, although most adults have learned to recognize and produce syntactically correct sentences, very few are, in fact, able to state the underlying rules of grammar. The purpose of the present article is twofold: (1) to describe a general framework for understanding implicit learning, and (2) to empirically test two of the predictions generated by the framework. The focus of our work is on implicit serial learning ${ }^{1}$-that is, the acquisition of serial information in the absence of explicit knowledge about the acquired information (see, e.g., Lewicki, Czyzewska, \& Hoffman, 1987).

We examine implicit serial learning by using a task originally introduced by Nissen and Bullemer (1987; see

\footnotetext{
This research was supported, in part, by a Research Council Grant from the graduate division of the University of Missouri, Columbia, to P.A.F. We thank Jody Crow, Staci Enger, David Foreman, Manuela Lascuola, Maggie Loewe, and Debbie Zukerman (Experiments 1 and 2), and Sophia Chernawsky, Jennifer Lin, Susan Montrey, Brent Schnieders, and Susan Woods (Experiment 3) for their assistance with data collection. We also thank Lenoir Retirement Community and Candlelight Retirement Home in Columbia, MO, for their help with recruiting the elderly subjects in Experiment 3 . Special thanks to Susan Barker and Janice Clark. Thanks also to Axel Buchner, Nelson Cowan, David Geary, Douglas Hintzman, Lynn Okagaki, Michael Stadler, Daniel Willingham, and an anonymous reviewer for insightful comments on earlier drafts of the article. Correspondence concerning this article should be addressed to P. A. Frensch, Department of Psychology, 210 McAlester Hall, University of Missouri, Columbia, MO 65211. (e-mail: psypeter@mizzoul.bitnet).
}

also Cohen, Ivry, \& Keele, 1990; Knopman, 1991; Knopman \& Nissen, 1987; Nissen, Knopman, \& Schacter, 1987; Nissen, Willingham, \& Hartman, 1989; Stadler, 1989,1992 ; Willingham, Nissen, \& Bullemer, 1989). In the Nissen and Bullemer task, an asterisk is presented at one of four different spatial locations that are arranged in a horizontal line on a computer screen. Each of the locations is mapped onto a different response key. The subjects' task is to press the key that corresponds to the asterisk's screen location. The asterisks are presented one at a time, and they follow either a repeating sequence or a random sequence of screen locations. Recent experiments with the Nissen and Bullemer task have primarily addressed three theoretical issues concerning explicit and implicit learning: (1) the independence of the implicit and explicit learning modes, (2) the role of attention in implicit learning, and (3) the nature of the learning mechanism(s) underlying implicit learning.

\section{Independence of Learning Modes}

In their original paper, Nissen and Bullemer (1987) reported that response times (i.e., indirect measures of task performance; henceforth RTs) decreased reliably faster with presentations of repeating sequences than with presentation of random sequences over practice trials. Furthermore, RTs increased reliably when repeating sequences were replaced by random sequences. However, direct measures of task performance (i.e., cued recall, predicting an event in the sequence, given preceding events as cues) showed that subjects had not necessarily been aware of the nature of the repeating sequence. Nissen and Bullemer interpreted the functional dissociation between direct and indirect measures of learning (see also 
Hebb, 1961; McKelvie, 1987) as evidence for an implicit mode of learning.

Further evidence for a functional dissociation between explicit and implicit modes of learning comes from another study reported by Nissen and Bullemer (1987), in which they found that patients with Korsakoff's syndrome could learn the repeating sequence, as was indicated by an indirect measure of serial learning (i.e., faster RTs), although the patients did not report awareness of the sequence. Similarly, scopolamine, an anticholinergic drug, appears to suppress awareness of the repeating sequence in normal subjects, but does not appear to affect the indirect measure of serial learning (Nissen et al., 1987). Moreover, Willingham et al. (1989) recently found that indirect measures (i.e., response times) and direct measures (i.e., generate task) of learning can develop independently with practice.

These results, although not unquestioned (see, e.g., Perruchet \& Amorim, 1992), are consistent with a relatively large body of similar findings based on different experimental paradigms (e.g., Berry \& Broadbent, 1984; Hayes \& Broadbent, 1988; Hebb, 1961; Lewicki et al., 1987; Lewicki, Hill, \& Bizot, 1988; Mathews et al., 1989; Reber, 1967, 1989; Servan-Schreiber \& Anderson, 1990), and they seem to indicate that serial information can indeed be learned in the absence of conscious awareness. The type of serial information that can be learned implicitly does not appear to be limited to sequences of spatial locations (see, e.g., Nissen \& Bullemer, 1987), but extends to sequences of verbal information as well (see, e.g., Hartman, Knopman, \& Nissen, 1989). Furthermore, implicit knowledge appears to be acquired through both perceptual experience (Fendrich, Healy, \& Bourne, 1991; J. H. Howard, Mutter, \& D. V. Howard, 1992; Stadler, 1989) and the execution of motor responses (e.g., Willingham et al., 1989), and the amount of learning does not appear to differ between college-aged and elderly adults (e.g., D. V. Howard \& J. H. Howard, 1989, 1992).

\section{The Role of Attention}

In their original set of experiments, Nissen and Bullemer (1987) found that implicit serial learning was eliminated when subjects were asked to perform a secondary task (i.e., tone counting) concurrently with the keypressing task (i.e., the Nissen \& Bullemer task). Nissen and Bullemer argued that the secondary task interfered with attention to the sequence of stimuli and that attention to the stimulus sequence was necessary for implicit learning to occur. More recently, however, Cohen et al. (1990; see also Frensch, Buchner, \& Lin, in press; Keele \& Jennings, 1992) have shown that at least some types of sequences can be learned under dual-task conditions. Although this would appear to indicate that implicit learning does not necessarily require attention, the issue of whether or not attention is needed for all forms of implicit learning is far from settled. Any empirical resolution of the issue would require not only a concise definition of attention but also the experimental manipulation of degree of attention to the sequencing of the primary task, something that has not been accomplished so far. However, to the extent that a secondary task can be said to interfere with attention to the primary, Nissen and Bullemer, task, it appears that implicit learning may occur in the absence of attention. Indeed, Cohen et al. (1990) and Curran and Keele (1993) distinguish between two different learning mechanisms that are responsible for implicit learning, only one of which requires attention.

\section{Learning Mechanisms Underlying Implicit Learning}

Nissen and Bullemer (1987) originally argued that learning of sequential information can be either declarative (with awareness) or procedural (without awareness), with both learning modes requiring attention. This contention was consistent with the assumption of a single learning mechanism underlying implicit learning. However, Cohen et al. (1990) reported differing amounts of implicit learning in the Nissen and Bullemer paradigm for three different types of repeating sequences: unique, ambiguous, and hybrid. In the unique sequences, every element of the repeating sequence had a unique association with the next element in the sequence (e.g., 12354, where the numbers 1-5 denote, from left to right, five screen locations at which the stimulus could appear). In the ambiguous sequences, each element was followed by two different elements at different serial positions in the repeating sequence (e.g., 123213). Finally, hybrid sequences contained both unique and ambiguous components (e.g., 123134).

Cohen et al. (1990) found that under dual-task conditions only the unique and the hybrid sequences were learned, but the ambiguous sequences were not learned. They (1990; see also Curran \& Keele, 1993) hypothesized that two different learning mechanisms may underlie implicit learning in the Nissen and Bullemer (1987) task: a mechanism that forms associations between sequentially presented stimuli, and a mechanism that forms hierarchical memory representations of stimulus configurations (Keele \& Summers, 1976). The authors hypothesized further that the associative mechanism may be capable of operating without attention, whereas the hierarchical mechanism may require attention.

Because Keele and Jennings (1992; see also Frensch et al., in press), more recently, have reported that even ambiguous sequences can be learned under dual-task conditions, we conclude that unique, ambiguous, and hybrid sequences can all be learned implicitly under dual-task conditions, although the degrees of learning differ among the three types of sequences. At present, we see no need to introduce two different, implicitly operating learning mechanisms. We assume that only one learning mechanism, a strictly associative process, is responsible for implicit learning in the Nissen and Bullemer paradigm, and that the effectiveness of the mechanism varies with the type of sequence that is to be learned (see Frensch et al., in press). The one-mechanism assumption is, in principle, 
consistent with recent computational models of serial learning that have been described by Cleeremans and McClelland (1991), Frensch (1991, in press; Frensch \& Geary, 1993), and Jordan (1986; Jordan \& Rumelhart, 1992).

\section{Toward a Model of Implicit Learning}

The results summarized above are consistent with the theoretical framework that we introduce below (see Figure 1). This framework is based on, and borrows rather heavily from, a model of the human information-processing system described by Cowan $(1988,1993)$. To relate implicit learning to a general framework of the cognitive system has, we believe, at least two advantages: it does not require any specific "machinery" for implicit learning, and it allows, at least in principle, for the possibility of theoretically integrating phenomena typically associated with implicit learning and implicit memory (see, e.g., Berry \& Dienes, 1991; Hintzman, 1990; Nelson, Schreiber, \& McEvoy, 1992). In general, we assume that learning in the Nissen and Bullemer paradigm involves the operation of (1) two functionally separable memory stores, short-term memory and long-term memory, and (2) a central executive that directs attention and controls voluntary processing. We assume, further, that short-term memory represents an activated subset of long-term memory (see, e.g., Cowan, 1993; Hebb, 1949), and that only a subset of the activated long-term memory may be in the focus of attention at any point in time.

Learning, whether explicit or implicit, is assumed to occur only in the subset of long-term memory that is currently active (i.e., a short-term store). At present, we favor a two-mechanism explanation for learning in the Nissen and Bullemer (1987) task. First, explicit learning is assumed to occur only in the subset of short-term mem-

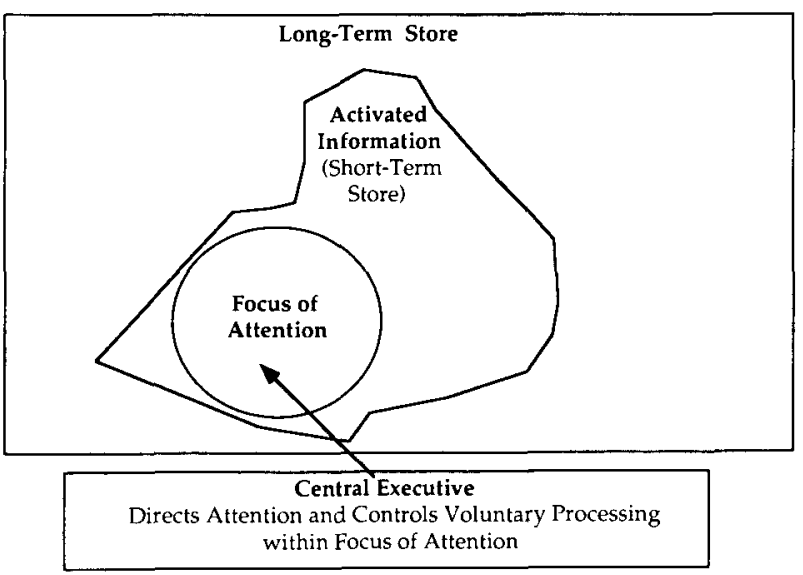

Figure 1. A general framework for understanding implicit and explicit learning. (Adapted from "Evolving conceptions of memory storage, selective attention, and their mutual constraints within the human information-processing system" by N. Cowan, 1988, Psychological Bulletin, 104, p. 180. Copyright 1988 by the American Psychological Association. Adapted with permission of the author.) ory that is in the focus of attention and is achieved through active processes (e.g., hypothesis testing) that are controlled by the central executive. Second, implicit learning involves activated information inside and/or outside the focus of attention and is achieved through a passive, strictly associative process (e.g., Cleeremans \& McClelland, 1991) that is capable of detecting and storing covariational environmental information. Implicit learning is not guided by the central executive. In the context of the Nissen and Bullemer task, the implicitly operating learning mechanism detects covariations between consecutively presented spatial locations.

According to the present framework, explicit and implicit learning differ in three important ways. First, explicit, but not implicit, learning is controlled by the central executive. We assume that controlled processing always leads to awareness. Thus, explicit learning leads to awareness, whereas implicit learning does not. Second, the two learning modes differ in the variety of learning processes that they support. Explicit learning supports a variety of learning processes that range from simple associative learning to hypothesis-guided learning. Implicit learning, in contrast, can be achieved by associative processes only. Finally, explicit learning results in more elaborate long-term memory coding than implicit learning does. Therefore, the results of explicit learning are more likely to be voluntarily retrievable from long-term memory than are the results of implicit learning.

The present framework is consistent with the main conclusions regarding implicit learning in the Nissen and Bullemer paradigm that were reached above. First, because explicit and implicit learning can be achieved by different mechanisms that lead to more or less elaborate long-term memory codings, the two modes of learning may result in dissociations, although they do not necessarily need to do so. Second, learning that is controlled by the central executive always results in awareness. Therefore, implicit learning must be based on processes that are performed automatically (see, e.g., Jacoby, Toth, \& Yonelinas, 1993) and do not require attention. Third, it is assumed, within the present framework, that only associative processes can be performed without the guidance of the central executive. Therefore, our assumption is that only one learning mechanism underlies implicit learning.

The framework makes a number of useful and interesting empirical predictions. For example, the framework predicts that a secondary task may interfere with both explicit and implicit learning, albeit for very different reasons. A secondary task is assumed to affect explicit learning to the extent that it is in need of guidance by the central executive. In contrast, a secondary task affects implicit learning to the extent that the task requires the activation of information in long-term memory that is identical to the information activated by the primary task. Because the tone-counting task, used by most researchers as a task secondary to the primary Nissen and Bullemer task, requires the process of mental addition, it is expected to interfere with the operation of the central executive. How- 
ever, in the typical Nissen and Bullemer situation, spatial information is utilized, whereas in the tone-counting task, nonspatial, perhaps phonological, information is utilized. Therefore, in this situation, implicit learning should not be affected by the secondary task. Indeed, recent results in our lab (Lin, Frensch, \& Buchner, 1993) have shown that the amount of implicit learning does not differ under single-task and dual-task conditions if tone counting is the secondary task employed. On the other hand, Goschke (1992), using a visual format for the secondary counting task, has found virtually no implicit serial learning under dual-task conditions.

The present framework is, in principle, not limited to describing learning in the Nissen and Bullemer task but can be extended to other serial pattern learning tasks (see, e.g., Lewicki et al., 1987; Lewicki et al., 1988; Stadler, 1989), artificial grammar learning tasks (e.g., Mathews et al., 1989; Reber, 1967, 1989; Servan-Schreiber \& Anderson, 1990), and perhaps even tasks that require the control of artificial computerized systems (e.g., Berry \& Broadbent, 1984; Hayes \& Broadbent, 1988). However, the strength of the present approach lies in providing a memory framework. The framework falls short of providing specific details of a general process account of implicit learning (see, e.g., Cleeremans \& McClelland, 1991; Frensch, in press; Keele \& Jennings, 1992), for two primary reasons. First, the tasks that are commonly thought of as reflecting implicit learning (i.e., serial pattern tasks, artificial grammar tasks, and system control tasks) differ in important ways and do not necessarily reflect the operation of the same implicit learning processes. Second, experimental findings that seemingly demonstrate the effects of certain variables on learning mechanisms may, in fact, simply reflect properties of the overall memory environment. It seems, thus, more appropriate to concentrate on establishing a common frame within which a variety of potential learning mechanisms may operate. This is indeed our intent.

One of the most important properties of our framework is the assumption that implicit learning occurs only in the subset of long-term memory that is activated. Following Cowan (1988), we assume that (1) the capacity of the short-term store is limited-that is, only a limited amount of long-term memory information can be activated at any point in time-and (2) the activation level of the activated subset of long-term memory decays with time. The experiments presented in this article represent a first attempt to empirically investigate the relation between implicit learning and short-term memory capacity and activation level. On the basis of our framework, we predict that the degree of implicit learning is a function of both the activation level of the information to be learned and the capacity of short-term memory. First, as stated above, implicit learning in the Nissen and Bullemer task corresponds to the detection of covariations between consecutively presented spatial locations. The present framework predicts that covariation detection and learning is affected by the activation level of the information that covaries. Covari- ation is learned only if the activation levels of all the participating pieces of information are above threshold (i.e., all the participating pieces of information are simultaneously available in short-term memory). Second, the capacity of short-term memory is predicted to affect implicit learning because the more information that can be activated at any time, the more associations the implicitly operating mechanism can potentially form.

The predicted relation between the two properties of short-term memory (i.e., limited capacity and activation level) and the degree of implicit serial learning is relatively unique to the present framework. For example, Berry and Broadbent (1988; see also Hayes \& Broadbent, 1988) also distinguish two modes of learning, which the authors label "s-mode" (selective mode) and "u-mode" (unselective mode). The selective mode of learning corresponds to what we refer to as the explicit learning mode; the unselective mode refers to our implicit learning mode. Berry and Broadbent argue that only the selective mode of learning operates within a decay-prone and capacitylimited type of working memory, whereas the unselective learning mode "does not reflect the operation of a cognitive subsystem such as AWM" (Hayes \& Broadbent, 1988 , p. 251), where AWM refers to an "abstract working memory" (Broadbent, 1984). Thus, implicit learning, according to Hayes and Broadbent, should not be affected by capacity limitations and activation level.

Similarly, Mathews et al. (1989) argue that implicit learning reflects a process that automatically extracts family resemblances among exemplars stored in long-term memory (see the memory array models described by Estes, 1986, and Dienes, 1992, for instance, for how such a process might operate). Therefore, implicit learning should not be affected by properties of short-term memory. Recent connectionist models of serial learning (see, e.g., Cleeremans \& McClelland, 1991; Keele \& Jennings, 1992) also do not predict a relation between the properties of short-term memory and the amount of implicit serial learning. Cleeremans and McClelland's model, for instance, does not include a decay mechanism and therefore does not predict that the activation level of information to be learned should affect implicit serial learning.

On the other hand, many of the early association-based models of serial learning (see, e.g., Estes, 1976; Falmagne, 1965; Laming, 1969) support the prediction that the activation level of information should affect serial learning. However, these models deal with explicit, not implicit, serial learning and also do not typically endorse the predicted link between short-term memory capacity and implicit learning. Thus, the present experiments test the assumptions of the framework introduced above and provide important empirical constraints for any model of implicit serial learning.

\section{EXPERIMENT 1}

The goal of Experiment 1 was to examine, under both incidental and intentional task instructions, the relation 
between implicit serial learning and the two properties of short-term memory discussed above. Implicit serial learning was assessed by an indirect, RT-based, measure. To measure short-term memory capacity, subjects received a computerized visual digit span task as well as a similar task that measured capacity for visually presented locations. ${ }^{2}$ We expected that larger short-term memory spans would allow for more implicit learning than would smaller spans.

The activation level of the to-be-learned information was varied by experimentally manipulating the rate of presentation in the Nissen and Bullemer task. Specifically, the time interval between subjects' responses and the presentation of the next stimulus (response-stimulus interval, or RSI) was set to be equal to either 500 or $1,500 \mathrm{msec}$. Given our framework, we expected that the degree of implicit learning would be larger when the to-be-learned stimuli were presented closer together in time-that is, when RSI was equal to $500 \mathrm{msec}$ rather than $1,500 \mathrm{msec}$.

Task instructions were either intentional or incidental. At the beginning of the experiment, the subjects in the intentional condition were told that the sequence of asterisks that they were to respond to was systematic. The subjects in the incidental condition were not made aware of the repeating sequence. The experimental task used in Experiment 1 differed from the original Nissen and Bullemer task described above in three respects: (1) the length of the repeating sequence was 12 , rather than 10 , stimuli; (2) the repeating sequence was randomly determined for each subject rather than the same for all subjects; and (3) random sequences were interspersed with the repeating sequence throughout the experiment.

Experiment 1 was divided into three phases. In the first phase, the subjects performed the two computerized memory span tasks. In the second phase of the experiment, the subjects performed the modified Nissen and Bullemer (1987) task. In the final phase, subjects performed the equivalent of Nissen and Bullemer's generate task, in which subjects, instead of responding to the present location of the stimulus, are asked to predict where the stimulus will appear next. The generate task is assumed to be a direct, rather than indirect, measure of serial learning and, therefore, to reveal the extent to which knowledge of the repeating sequence has been learned explicitly rather than implicitly.

\section{Method}

Subjects. The subjects were 27 male and 42 female undergraduate students at the University of Missouri, Columbia, who received course credit in introductory psychology for participating. They ranged in age from 18 to 22 years.

Stimuli and Apparatus. All stimuli were $0.50 \times 0.50 \mathrm{~cm}$ in size and were presented on a Macintosh SE microcomputer. For the digit span task, a digit (ranging from 1 to 9) was shown at the center of the screen. For the location span task, the screen was divided into four equal quadrants. The stimulus was an asterisk that could appear at the center of each of the quadrants. For the digit span and location span tasks, responses to each trial were written on sheets of paper provided by the experimenter.
In the experimental task, the stimulus was an asterisk centered at one of four horizontal locations, $5.20 \mathrm{~cm}$ below the top of the monitor. The locations were underlined, so that the asterisk appeared above one of the lines. The viewing distance was approximately $60 \mathrm{~cm}$. Responses were made by pressing one of four keys on the second row from the bottom on the microcomputer keyboard. The keys for the letters " $\mathrm{Z}$ " and " $\mathrm{C}$ " could be pressed with the left middle and index fingers; the keys " 1 " and " 3 " (number pad) could be pressed with the right index and middle fingers.

Procedure. The subjects were tested individually. Instructions for all the tasks were presented on the screen. For the digit span task, the subjects were shown random sequences of digits (excluding repetitions and runs) with defined lengths. The digits were shown one at a time for $500 \mathrm{msec}$ each. All subjects started with a sequence length of three. The sequences systematically increased in length from 3 to 12 , with each length represented by two different sequences. When the last digit in a sequence had been presented, a beep sounded, and the subjects were prompted to write down the entire sequence of digits in their correct order. When the subjects were ready to continue, they hit the space key, and the next sequence was presented.

The location span procedure was essentially identical to the digit span procedure, except that asterisks were shown and the stimuli appeared at the center of one of the quadrants on the screen. Again, sequences increased in length from 3 to 12 , and each length was represented by two different sequences. When the last asterisk had been presented, a beep sounded, and the subjects wrote down the entire sequence of locations on a sheet of paper. To facilitate the subjects' responses, the sheet of paper was divided into quadrants, and they were asked to write a "1" in the quadrant where the first asterisk had appeared, a " 2 " in the quadrant where the second asterisk had appeared, and so on. On both the digit span and the location span task, the subjects received four practice trials with a sequence length of two. In both tasks, short-term memory capacity was determined as the first length, minus one, at which subjects failed to correctly recall both presented sequences.

In the incidental presentation condition, the presence of a repeating sequence was not revealed to the subjects. In the intentional presentation condition, in contrast, they were told that the sequence of asterisks followed a systematic and repeating pattern, and that they could save time and effort by detecting the pattern. The subjects were instructed to respond as quickly as possible without making errors.

Each subject received a different, semirandomly determined, repeating sequence of length 12 , as well as different random sequences. All repeating sequences were selected in such a way that no location could occur twice on consecutive trials, no runs of length 3 or higher could occur (locations 1-2-3, 2-3-4, 1-2-3-4, 4-3-2, 3-2-1, 4-3-2-1), and each location occurred exactly three times. The random sequences were randomly selected for each subject, with the constraint that any overlap between random and repeating sequence was limited to a length of, at most, three locations.

To acquaint the subjects with the experimental task, they received 10 practice trials, during which the asterisk appeared at random at one of the four locations, with the constraint that it could not appear at the same location on consecutive trials. During the practice trials only, the location numbers " $1-4$ " were presented above the asterisks to facilitate subjects' associating the four locations with the correct response keys.

After the practice trials, the subjects completed a total of five blocks of experimental trials. Within each trial block, the repeating sequence occurred 10 times; random sequences were presented 3 times. The random sequences were shown after the repeating sequence had been presented 2 times, 5 times, and 8 times. Successive trial blocks were separated by a short rest period, the duration of which was determined by the subject. 
In the generate task, the subjects were asked to indicate where the asterisk would appear next by pressing the corresponding key. The instructions clearly stated that, throughout most of the experiment, a single sequence of positions had been continuously recycled, and asked the subjects to recall this sequence. ${ }^{3}$ Accuracy was emphasized, and the subjects were told that RTs would no longer be recorded. The generate task involved a single block of 120 trials (i.e., 10 cycles with the correct repeating sequence).

\section{Results}

For clarity of presentation, the results are organized into three main sections. The first section contains the results of the experimental manipulation of RSI and type of instruction on the indirect, RT, measure of serial learning. The second section covers the findings obtained with the generate task, and the third contains the results pertaining to the relation between indirect measures of serial learning and the measures of digit and location short-term memory capacity.

Effects of type of instruction and RSI on the indirect measure of serial learning. Overall, subjects made relatively few errors in the experimental keypressing task. Mean error rates ranged from $2.0 \%$ to $3.4 \%$ across conditions. Table 1 presents the means and standard deviations of subject median RTs for the repeating and the random sequences in the four experimental conditions. The mean RT difference between repeating and random sequences is presented in Figure 2 as a function of block of trials and experimental condition. The RT difference can be interpreted as reflecting the degree to which the repeating sequence was learned. As can be seen in Figure 2, the difference decreased for both the incidental and the intentional 500 -msec conditions across the five trial blocks, but did not change much for the two $1,500-\mathrm{msec}$ conditions.

The difference scores of Figure 2 were examined by a 2 (type of instruction: intentional vs. incidental) $\times 2$ (RSI: 500 vs. $1,500 \mathrm{msec}) \times 5$ (trial block: $1-5)$ mixed-

Table 1

Average Response Times (in Milliseconds) for Repeating and Random Sequences as a Function of Experimental Condition and Block of Trials (Experiment 1)

\begin{tabular}{|c|c|c|c|c|c|c|c|c|c|c|}
\hline \multirow[b]{3}{*}{ Sequence } & \multicolumn{10}{|c|}{ Trial Block } \\
\hline & \multicolumn{2}{|c|}{1} & \multicolumn{2}{|c|}{2} & \multicolumn{2}{|c|}{3} & \multicolumn{2}{|c|}{4} & \multicolumn{2}{|c|}{5} \\
\hline & $M$ & $S D$ & $\bar{M}$ & $S D$ & $M$ & $S D$ & $M$ & $S D$ & $M$ & $S D$ \\
\hline \multicolumn{11}{|c|}{ Incidental, RSI $=500 \mathrm{msec}$} \\
\hline Repeating & 496 & 84 & 488 & 74 & 478 & 74 & 473 & 76 & 469 & 79 \\
\hline n & 500 & 83 & 495 & 77 & 497 & 85 & 498 & 94 & 499 & 103 \\
\hline \multicolumn{11}{|c|}{ Incidental, $R S I=1,500 \mathrm{msec}$} \\
\hline Repeating & 515 & 85 & 535 & 119 & 514 & 107 & 507 & 111 & 503 & 119 \\
\hline Random & 512 & 79 & 525 & 110 & 510 & 105 & 507 & 110 & 505 & 118 \\
\hline \multicolumn{11}{|c|}{ Intentional, RSI $=500 \mathrm{msec}$} \\
\hline Repeating & 537 & 126 & 509 & 95 & 485 & 82 & 469 & 82 & 458 & 81 \\
\hline Random & 548 & 127 & 526 & 96 & 513 & 87 & 504 & 92 & 497 & 100 \\
\hline \multicolumn{11}{|c|}{ Intentional, RSI $=1,500 \mathrm{msec}$} \\
\hline Repeating & 534 & 159 & 519 & 147 & 510 & 144 & 502 & 144 & 498 & 145 \\
\hline Random & 535 & 155 & 522 & 140 & 516 & 134 & 512 & 134 & 510 & 133 \\
\hline
\end{tabular}

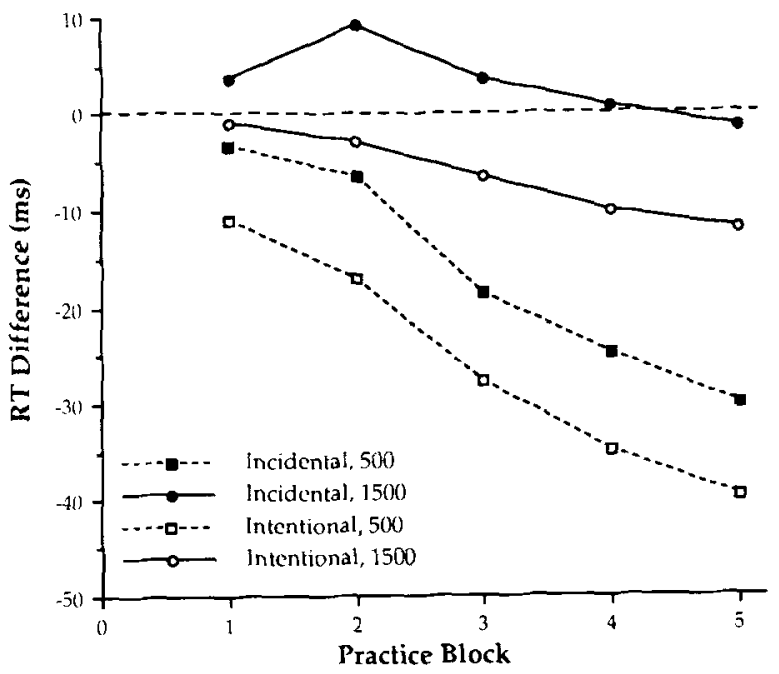

Figure 2. Mean RT difference (RTrepeating - RTrandom) as a function of type of instruction, RSI, and block of trials (Experiment 1).

design analysis of variance (ANOVA). This analysis indicated reliable main effects of type of instruction $[F(1,65)$ $\left.=14.51, M S_{\mathrm{e}}=2,295, p<.001\right]$ and of trial block $\left[F(4,260)=11.88, M S_{e}=359, p<.001\right]$, as well as a marginally reliable main effect of $\operatorname{RSI}[F(1,65)=3.38$, $\left.M S_{e}=2,295, p<.07\right]$. Only the interaction between trial block and RSI was reliable $\left[F(4,260)=3.05, M S_{\mathrm{e}}=\right.$ $359, p<.05$; for all other interactions, $p>.73$ ].

Because the variances of the difference scores varied considerably for the intentional and incidental task instruction conditions (Myers, 1979; Winer, 1971), we ran separate ANOVAs for the intentional and incidental task instruction conditions. ${ }^{4}$ These analyses revealed reliable main effects of RSI and trial block in both conditions $\left[F(1,33)=12.02, M S_{\mathrm{e}}=1,410, p<.01\right.$, and $F(4,132)$ $=8.19, M S_{e}=238, p<.001$, for the effects of RSI and trial block in the incidental condition, respectively; and $F(1,32)=5.10, M S_{\mathrm{e}}=3,208, p<.05$, and $F(4,128)$ $=4.91, M S_{\mathrm{e}}=482, p<.01$, for the effects of RSI and trial block in the intentional condition, respectively]. The interaction between trial block and RSI was reliable in the incidental instruction condition $[F(4,132)=2.75$, $\left.M S_{e}=238, p<.05\right]$, but it was not reliable in the intentional condition $(F<1)$.

These analyses indicate that both type of instruction and RSI had reliable effects on the indirect, RT, measure of serial learning. Not surprisingly, the subjects in the intentional instruction condition learned the repeating sequence better than the subjects in the incidental condition. More importantly, the subjects in the two RSI $=500 \mathrm{msec}$ conditions learned the repeating sequence better than did the subjects in the two RSI $=1,500 \mathrm{msec}$ conditions. In fact, the subjects in the RSI $=1,500 \mathrm{msec}$ conditions did not appear to learn the repeating sequence at all, as indicated by nonreliable main effects of trial block $[F(4,64)=$ 
$1.30, M S_{\mathrm{e}}=207, p>.27$, and $F(4,60)=1.06, M S_{\mathrm{e}}=$ $336, p>.38$, for the incidental and intentional presentation conditions, respectively]. In contrast, for both of the RSI $=500$ msec conditions, the effect of trial block was reliable $\left[F(4,68)=8.94, M S_{\mathrm{e}}=268, p<.001\right.$, and $F(4,68)=4.25, M S_{\mathrm{e}}=612, p<.01$, for the incidental and intentional presentation conditions, respectively]. These findings indicate that an RSI of $500 \mathrm{msec}$ led to better learning of the repeating sequence than did an RSI of $1,500 \mathrm{msec}$ under both incidental and intentional instructions.

Generate task: Direct measure of serial learning. Figure 3 contains the results of the generate task for the four experimental conditions across the 10 prediction trial blocks. Recall that the generate task was assumed to capture the extent to which the repeating task had been learned explicitly. Three results depicted in Figure 3 deserve mention. First, considering initial (trial $=1$ ) task performance, the subjects in the intentional instruction conditions were better at predicting the repeating sequence than the subjects in the incidental conditions, as one would expect $\left[F(1,64)=5.27, M S_{\mathrm{e}}=0.041, p<.05\right]$. Neither the effect of RSI nor the interaction between type of instruction and RSI was reliable (both $F \mathrm{~s}<1$ ). (An analysis using the arcsine transformation on the percent correct scores [see, e.g., Winer, 1971] yielded identical results.) The mean percentages correctly predicted were $28 \%$, $23 \%, 37 \%$, and $37 \%$ for the incidental 500 -msec, incidental $1,500-\mathrm{msec}$, intentional $500-\mathrm{msec}$, and intentional $1,500-\mathrm{msec}$ conditions, respectively. If one considers that the expected value, under random guessing, would be $33 \%$ if subjects learned that the same location never occurred twice in a row, and $25 \%$ if subjects did not learn anything, it becomes clear that the amount of explicit serial learning demonstrated in this task was very small.

Second, in the incidental instruction conditions, the initial performance of the RSI $=500 \mathrm{msec}$ condition was

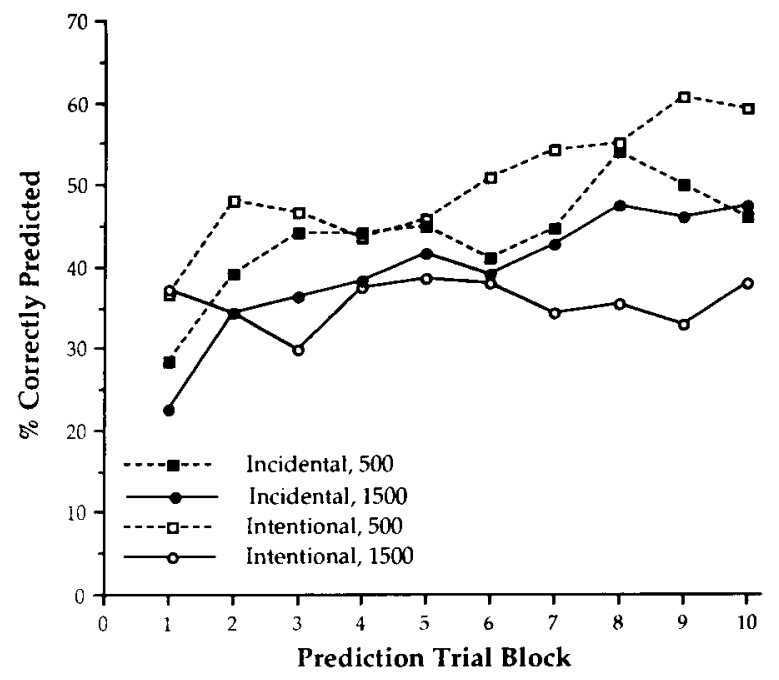

Figure 3. Mean percent correctly predicted as a function of type of instruction, RSI, and trial block (Experiment 1).
Table 2

Correlations Between Measures of Short-Term Memory

Capacity and Indirect Measure of Serial Learning as a

Function of Experimental Condition (Experiment 1)

\begin{tabular}{lllrc}
\hline \multirow{2}{*}{$\begin{array}{lll}\text { Instruction } \\
\text { Condition }\end{array}$} & Measure & \multicolumn{3}{c}{ RSI } \\
\cline { 3 - 5 } Incidental & Location span & -0.11 & 1,500 & \multicolumn{1}{c}{ All } \\
& Digit span & -0.13 & -0.07 & -0.09 \\
Intentional & Location span & $-0.57^{*}$ & 0.15 & -0.13 \\
& Digit span & -0.34 & -0.15 & -0.22 \\
All & Location span & $-0.35^{*}$ & 0.05 & \\
& Digit span & -0.23 & -0.14 \\
\hline Note-Correlations are based on varying sample sizes. & ${ }^{*} p<.05$.
\end{tabular}

better than that of the RSI $=1,500$ msec condition. Although this difference was not reliable and in both cases did not exceed random performance, it raises the question of whether the advantage of the RSI $=\mathbf{5 0 0} \mathrm{msec}$ condition over the RSI $=1,500 \mathrm{msec}$ condition on the indirect measure of serial learning might have been due to the fact that the subjects in the RSI $=500$ msec condition were more aware of the repeating sequence than the subjects in the RSI $=1,500$ msec condition. To clarify this possibility, the analyses described in the previous section for the incidental instruction conditions were rerun, after all the subjects in the RSI $=500$ msec condition whose initial (Trial 1) prediction score was higher than $50 \%$ had been removed $(N=5)$. The removal of the subjects resulted in a new mean score of $19 \%$ correct for the remaining subjects on the generate task (compared with a mean of $23 \%$ correct in the incidental 1,500 -msec condition), but did not qualitatively affect the results of the analyses described in the previous section.

Third, the rate of learning appeared to be relatively constant in all experimental conditions (improvements of roughly $20 \%-25 \%$ over the 10 prediction trials) except the intentional 1,500-msec condition. The subjects in the latter condition did not improve their prediction scores at all over the 10 practice trials. Although this finding is interesting, we do not, at present, have a satisfying explanation for it. It may simply have been that the subjects in this condition, who had been told in advance that a repeating pattern existed, were discouraged by their inability to find the pattern during Experimental Phase 2 and did not believe they could do any better during the generate phase.

Relation between memory span measures and indirect measure of serial learning. Across all experimental conditions, the mean digit span was $8.07(S D=1.30)$, while the mean location span was $7.99(S D=1.64)$. The correlation between the two measures of short-term memory capacity was $r(67)=0.55, p<.01$. The patterns of correlations with the indirect, RT, measure of serial learning were very similar for the two measures of shortterm memory capacity, as is apparent in Table 2.

As can be seen in Table 2, the correlations were the largest in the intentional 500 -msec condition although the correlation with digit span did not reach significance. 
Thus, short-term memory capacity was reliably related to performance on the indirect measure of serial learning only under intentional instructions and only when RSI was equal to $500 \mathrm{msec}$.

\section{Discussion}

The main purpose of Experiment 1 was to test whether an indirect measure of serial learning was related to two aspects of short-term memory: (1) the activation level of the to-be-learned information, operationalized as rate of presentation; and (2) short-term memory capacity, as measured by digit and location spans. Experiment 1 yielded two main results. First, presentation rate affected the indirect measure of serial learning. Performance on the indirect measure of serial learning was better when RSI $=500 \mathrm{msec}$ than when $\mathrm{RSI}=1,500 \mathrm{msec}$, under both intentional and incidental task instructions. Second, short-term memory capacity was reliably related to the indirect measure of serial learning in the intentional 500msec condition, but not in the remaining experimental conditions.

RSI affected only the indirect measure of learning, but did not appear to affect the direct measure of serial learning, at least when only the first block of trials on the generate task was considered. Later trial blocks are not pure reflections of subjects' explicit knowledge of the repeating sequence, because all subjects were told, at the beginning of the generate phase, that there was, in fact, a repeating sequence, and thus could easily have learned the sequence by simply attending to the pattern of locations that was presented.

The RSI effect on the indirect measure of serial learning was as expected, and it is consistent with the assumptions outlined in the introduction. Apparently serial learning in the modified Nissen and Bullemer task is more likely to occur when the stimuli are presented closer together in time-that is, when the likelihood that the stimuli are simultaneously active in short-term memory is relatively high - than when the stimuli are presented farther apart in time. This is true under both incidental and intentional task instructions.

However, although the assumption that RSI affected the activation level of the individual stimuli in the Nissen and Bullemer task is reasonable, it cannot be confirmed with certainty, because decay effects can never be directly observed in any experimental setup. It is conceivable that RSI affected the amount of interference in addition to, or instead of, the level of activation. Thus, one may argue that an RSI of $1,500 \mathrm{msec}$ leads to less implicit learning than does an RSI of $500 \mathrm{msec}$, because the amount of interference is potentially larger in the former case than in the latter. Although we cannot rule out this possibility with certainty, we argue that the likelihood that interference determined our results was relatively small, given that the RSI intervals were unfilled for subjects in all conditions.

The correlational findings obtained in Experiment 1 were not completely consistent with our predictions. Short-term memory capacity was reliably correlated with degree of serial learning only in the intentional 500-msec condition, but not in any of the other conditions. Although at first surprising, this particular finding may be explained as a floor effect within the present framework. If one assumes that subjects in all but the intentional 500 -msec conditions learned only small parts of the repeating sequence, then no effect of short-term memory capacity would be expected, simply because small parts of the sequence can be activated by any subject without reaching the capacity limits. If one assumes, in addition, that the subjects in the intentional 500-msec condition learned larger parts of the repeating sequence, one would expect capacity problems to arise for subjects with smaller short-term memory capacities.

Because a reliable correlation between short-term memory capacity and degree of implicit learning can be expected only in experimental conditions in which the capacity limits are reached by at least some of the subjects, it was desirable to reexamine the relation between shortterm memory capacity and degree of serial learning in a situation in which a floor effect was highly unlikely. There appear to be at least two possibilities for protecting against a floor effect, both of which were realized in Experiment 2: (1) to decrease the difficulty (i.e., length) of the repeating sequence, and (2) to add a secondary task to the experimental task. The secondary task was expected to tap some of the capacity in short-term memory in such a way that capacity limitations in coping with the primary task would become more apparent.

\section{EXPERIMENT 2}

The primary goals of Experiment 2 were to replicate the main findings of Experiment 1 and to reexamine the relation between short-term memory capacity and an indirect measure of serial learning. In Experiment 2, all task instructions were incidental; that is, subjects were not informed of the presence of a repeating sequence. Otherwise, Experiment 2 was similar to Experiment 1, except that the original Nissen and Bullemer task was used instead of the modified task, and Experimental Phase 3 (generate task) was dropped in favor of a more direct approach in which subjects were asked to report any parts of the repeating sequence they could recall (i.e., a free recall task). For the experimental task, the subjects performed eight trial blocks on the repeating sequence (now of length six) and were then switched to a random sequence for two additional trial blocks. Here, the indirect measure of serial learning was the difference in RT between the last trial block with the repeating sequence (i.e., Block 8) and the first trial block with the random sequences (i.e., Block 9).

Both RSI ( 500 vs. $1,500 \mathrm{msec}$ ) and task load (single vs. dual task) were experimentally manipulated (between subjects). It was expected that RSI would affect the indirect measure of serial learning, as it did in Experiment 1 , and that short-term memory capacity would correlate higher with the indirect measure of serial learning 
under dual-task than under single-task conditions. The latter expectation was based on the reasoning that a secondary task would essentially reduce subjects' available short-term memory capacity and would thus eliminate a potential floor effect. The secondary task used in this experiment was the same tone-counting task that was used by Cohen et al. (1990), and by Frensch et al. (in press). A tone was presented in each RSI in the primary keypressing task. The tone was either high pitched or low pitched, and after each block of trials, the subjects were asked to report the number of high-pitched tones that they had heard throughout the previous block.

\section{Method}

Subjects. The subjects were $\mathbf{4 2}$ male and 71 female undergraduate students, at the University of Missouri at Columbia, who received course credit in introductory psychology for participating. The subjects ranged in age from 18 to 38 years.

Stimuli and Apparatus. The stimuli and apparatus for the two short-term memory capacity tasks and the primary keypressing task were the same as in Experiment 1. The stimuli for the secondary tone-counting task were low-pitched $(1000-\mathrm{Hz})$ and high-pitched $(2500-\mathrm{Hz})$ tones that were generated by the computer and were played through the computer's external loudspeakers. Tone onset occurred 40,80 , or $120 \mathrm{msec}$ (randomly selected) after subjects had responded to the primary keypressing task. The duration of the tones was $50 \mathrm{msec}$. Responses to the secondary task were made by typing a number on the number pad.

Procedure. The procedures for the two short-term memory capacity tasks, digit span and location span, were the same as in Experiment 1 . Both tasks were performed, in random order, before the experimental task began.

The experimental task was similar to that in Experiment 1; however, the sequence length for the repeating sequence was reduced to 6 , and the generate phase was replaced by a free recall test. All subjects completed eight blocks of trials during which a repeating sequence was continuously recycled ( 20 sequences per trial block). When they had completed the eight trial blocks, the subjects received two blocks of trials with random sequences of stimuli. Following the random sequences, the subjects were switched back to the repeating sequence for two additional trial blocks. Successive trial blocks were separated by a short rest period, the duration of which was determined by the subject.

Each subject received a different, semirandomly selected, repeating sequence of length six. All repeating sequences were derived from one of three different structural patterns: 123243, 143132, and 142312. To determine the repeating sequence for any given subject, first one of the three structural patterns was randomly selected. Then, Screen Locations 1-4 were randomly assigned to the events within the sequence such that the structural pattern was maintained. For example, if the selected structural pattern was 123243 , then, in terms of screen locations, both 321241 and 432312 were possible repeating sequences.

Half the subjects performed only the keypressing task (singletask condition). The remaining subjects performed the tone-counting task in addition to the keypressing task (dual-task condition). For the tone-counting task, the subjects were instructed to count the number of high-pitched tones, ignoring the low-pitched ones, for each block of trials. After each trial block, the subjects were asked to report the number of high-pitched tones and to set the tone count back to zero for the next block of trials. The sequence of high-pitched and low-pitched tones was randomly determined for each subject in such a way that the probability of a high-pitched tone's occurring was .55 . The actual number of high-pitched tones presented within a trial block ranged from 50 to 83 . The subjects were not given feedback on their performances on the tone-counting and keypressing tasks.

Each subject received 40 practice trials. During the practice trials, the asterisks appeared randomly at the four locations, with the restriction that the same location could not be used on consecutive trials. For the subjects in the dual-task condition, the secondary, tone-counting, task was introduced after they had completed 20 practice trials on the primary task. When they had completed all 12 trial blocks on the task, the subjects were asked a series of questions, proceeding from general to specific, assessing their explicit knowledge of the repeating sequence.

\section{Results}

Experimental task: Indirect measure of serial learning. As in Experiment 1, subjects made relatively few errors in the experimental task. Mean error rates ranged from $1.7 \%$ to $2.2 \%$ across conditions. For the subjects in the dual-task conditions, the number of high-pitched tones presented in each of the 12 trial blocks was compared with the reported number of high-pitched tones. All subjects for whom the reported number of high-pitched tones differed from the actual number presented by more than $10 \%$, on the average across all trial blocks, were discarded. Through the use of this procedure, data for 8 subjects in the dual-task 500 -msec condition and 10 subjects in the dual-task 1,500 -msec condition were deleted from all reported data analyses, resulting in 24 remaining subjects in the dual-task 500-msec condition and 23 remaining subjects in the dual-task 1,500 -msec condition.

Figure 4 presents the means of subject median RTs in the four experimental conditions over the 12 trial blocks. A 2 (task load: single vs. dual task) $\times 2$ (RSI: 500 vs. $1,500 \mathrm{msec}$ ) $\times 8$ (trial block: 1-8) mixed-design ANOVA of the RTs for the initial eight trial blocks yielded a reliable main effect of task load $\left[F(1,91)=52.60, M S_{\mathrm{e}}=\right.$ $191,902, p<.001]$ and of trial block $[F(7,637)=$ $\left.165.59, M S_{\mathrm{e}}=2,229, p<.001\right]$. The main effect of RSI

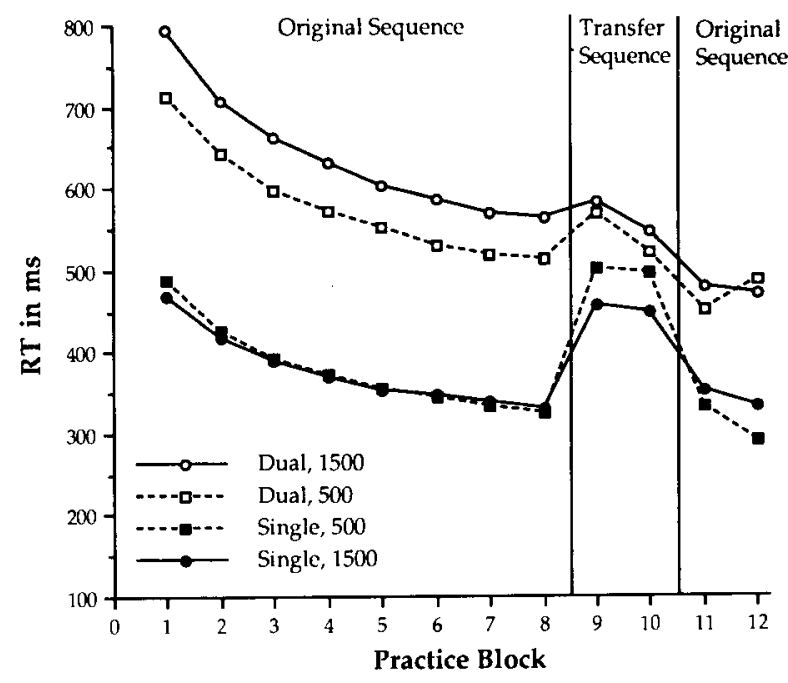

Figure 4. Mean response time as a function of task load, RSI, and block of trials (Experiment 2). 
was not reliable $(F<1)$. Only the interaction between task load and trial block was reliable $[F(7,637)=5.99$, $\left.M S_{\mathrm{e}}=2,229, p<.001\right]$, indicating that RTs for the dualtask conditions decreased more between Trial Blocks 1 and 8 than RTs for the single-task conditions. All other interactions were not reliable $(F \mathrm{~s}<1)$.

Of more importance were the effects of task load and RSI on the indirect measure of serial learning. Degree of learning was quantified as the mean difference in RT between Trial Blocks 8 and 9 (RT8-RT9). The mean difference scores were $177,126,57$, and $21 \mathrm{msec}$, for the single-task 500-msec, single-task 1,500-msec, dual-task 500 -msec, and dual-task 1,500-msec conditions, respectively. A 2 (task load: single vs. dual task) $\times 2$ (RSI: 500 vs. $1,500 \mathrm{msec}$ ) ANOVA of the difference scores yielded reliable main effects of task load $[F(1,91)=$ 85.75, $\left.M S_{\mathrm{e}}=4,604, p<.001\right]$ and RSI $[F(1,91)=$ $8.41, M S_{\mathrm{e}}=4,604, p<.01$ ], but no reliable interaction between task load and RSI $(F<1)$.

Separate ANOVAs for the single-task and dual-task conditions revealed a reliable main effect of RSI for both the single-task conditions $\left[F(1,46)=4.67, M S_{\mathrm{e}}=6,701\right.$, $p<.05]$, and the dual-task conditions $[F(1,45)=5.04$, $\left.M S_{\mathrm{e}}=2,999, p<.05\right]$. These results indicate that RSI affected the indirect measure of serial learning under both single- and dual-task conditions.

One might argue that any effect of RSI on the indirect measure of learning should show up not only in the RT difference between Trial Blocks 8 and 9, but also in the difference between Blocks 10 and 11 -that is, when the switch back from random sequences to the repeating sequences occurs. We did not analyze the transition from Block 10 to 11, however, because we do not believe that this transition necessarily reflects the degree to which implicit learning of the repeating sequence occurs. First, the switch to the random sequence might alert.subjects that "something is going on" in the experiment and might therefore affect their subsequent task strategies. Second, when subjects get close to the end of the experiment, fatigue and boredom, or both, might affect their task performance. By limiting our analyses to Trial Blocks 8 and 9, we avoid these potential problems and also follow a trend that has been established by other researchers in the area (e.g., Cohen et al., 1990; Curran \& Keele, 1993; D. V. Howard \& J. H. Howard, 1989, 1992).

Interestingly, although the analysis of Blocks 8 and 9 indicated that subjects in the single-task conditions had learned the repeating sequence much better than had subjects in the dual-task conditions, the analysis of Trial Blocks 1-8 appears to support the opposite conclusion. That is, the RTs for the dual-task conditions decreased reliably more between Trial Blocks 1 and 8 than did the RTs for the single-task conditions. Whereas the RT improvement for the single-task conditions reflects pure taskrelated changes, the improvement for the dual-task conditions reflects improvements in the primary task and the secondary task, as well as in the scheduling of the two tasks. If one makes the assumption that performance in the two tasks and in the scheduling of the two tasks approaches asymptote by Trial Block 8 , it is clear that the analysis of difference scores should be a more realistic assessment of the amount of learning in the dual-task conditions than the analysis of the difference between Trial Blocks 1 and 8.

Free recall: Direct measure of serial learning. The sequences recalled by subjects were scored according to whether or not they represented correct parts of the repeating sequence. A recalled sequence was scored as partially correct when more than two, but fewer than all six, successive locations were correctly recalled. The results of this analysis are summarized in Table 3.

Because a substantial number of subjects was able to at least partially recall the repeating sequence, we reran all of the analyses described in the previous section after discarding all subjects who correctly recalled parts of or the entire repeating sequence in the free recall task. Although the new analyses had lower statistical powerespecially in the single-task conditions-leading to fewer statistically reliable results than in the previous analyses, the pattern of findings obtained was qualitatively identical to that reported in the previous sections.

Relation between memory span measures and indirect measure of serial learning. Across all experimental conditions, the mean digit span was $8.17(S D=1.44)$, while the mean location span was $7.51(S D=2.10)$. The correlation between the two measures of short-term memory capacity was $r(93)=0.61, p<.001$. As in Experiment 1 , the pattern of correlations with the indirect, RT, measure of serial learning was remarkably similar for the two measures of short-term memory capacity, as is apparent in Table 4.

As can be seen in the table, the correlation between short-term memory capacity and the indirect measure of serial learning was reliable only in the dual-task $500-\mathrm{msec}$

Table 3

Free Recall Results in Experiments 2 and 3

\begin{tabular}{cccccccc}
\hline & \multicolumn{3}{c}{ Experiment 2 } & & \multicolumn{3}{c}{ Experiment 3 } \\
\cline { 2 - 4 } \cline { 6 - 8 } Task & RSI & Parts/Entire & Entire & & Age & Parts/Entire & Entire \\
\hline Single & $500 \mathrm{msec}$ & 70 & 59 & & Young & 88 & 69 \\
& $1,500 \mathrm{msec}$ & 67 & 52 & & Elderly & 88 & 50 \\
Dual & $500 \mathrm{msec}$ & 25 & 4 & & Young & 27 & 9 \\
& $1,500 \mathrm{msec}$ & 13 & 4 & & Elderly & 27 & 3 \\
\hline
\end{tabular}

Note-Parts/Entire $=$ percentages of subjects who correctly recalled parts of or entire repeating sequence. Entire $=$ percentages of subjects who correctly recalled entire repeating sequence. 
Table 4

Correlations Between Measures of Short-Term Memory Capacity and Indirect Measure of Serial Learning as a Function of Experimental Condition (Experiment 2)

\begin{tabular}{|c|c|c|c|c|}
\hline \multirow{2}{*}{$\begin{array}{l}\text { Task Load } \\
\text { Condition }\end{array}$} & \multirow[b]{2}{*}{ Measure } & \multicolumn{3}{|c|}{ RSI } \\
\hline & & 500 & 1,500 & All \\
\hline Single task & $\begin{array}{l}\text { Location span } \\
\text { Digit span }\end{array}$ & $\begin{array}{l}-0 . \overline{18} \\
-0.20\end{array}$ & $\begin{array}{l}-0.23 \\
-0.20\end{array}$ & $\begin{array}{l}-0.20 \\
-0.21\end{array}$ \\
\hline Dual task & $\begin{array}{l}\text { Location span } \\
\text { Digit span }\end{array}$ & $\begin{array}{l}-0.61 \dagger \\
-0.49^{*}\end{array}$ & $\begin{array}{r}-0.11 \\
0.13\end{array}$ & $\begin{array}{l}-0.38 \dagger \\
-0.16\end{array}$ \\
\hline All & $\begin{array}{l}\text { Location span } \\
\text { Digit span }\end{array}$ & $\begin{array}{l}-0.40 \dagger \\
-0.33^{*}\end{array}$ & $\begin{array}{r}-0.16 \\
0.00\end{array}$ & \\
\hline
\end{tabular}

condition. Two aspects of this finding are important. First, the nonreliable correlations in the single-task conditions are consistent with the null findings obtained in Experiment 1 . Second, the reliable correlation in the dual-task 500 -msec condition is consistent with the floor-effect explanation offered in Experiment 1, and it supports the assumption of an implicit learning mechanism operating in a capacity-limited short-term memory.

\section{Discussion}

The main purposes of Experiment 2 were to replicate the effect of RSI on an indirect measure of serial learning under incidental task instructions and to reassess the relation between individual differences in short-term memory capacity and an indirect measure of serial learning in a dual-task situation. Experiment 2 yielded two main results. First, presentation rate affected the indirect measure of serial learning under both single- and dualtask conditions. Performance on the indirect measure of serial learning was better when RSI $=500 \mathrm{msec}$ than when RSI $=1,500$ msec under both single- and dual-task conditions. Second, short-term memory capacity was reliably correlated with the indirect measure of serial learning under dual-task conditions, but only when RSI = $500 \mathrm{msec}$, and it was not reliably correlated with degree of implicit learning in any of the remaining experimental conditions.

It may appear somewhat surprising that short-term memory capacity was not reliably correlated with the indirect measure of implicit learning under single-task conditions. After all, we had changed the length of the repeating sequence from 12 in Experiment 1 to 6 in Experiment 2 , in the expectation that a reduction in sequence complexity would increase the size of the association patterns formed by the implicit learning mechanism. It appears, however, that by reducing the sequence length to 6 we decreased the size of even the largest possible association pattern to the point at which it did not reach the capacity limit of subjects. Thus, we essentially turned the floor effect of Experiment 1 into a ceiling effect. Note that this explanation is consistent with the results obtained with the explicit measure of learning discussed above. It appears that, in general, a reliable correlation can be ob- tained only when at least for some subjects within a condition implicit learning is constrained by the available capacity. The likelihood that this situation occurs is higher in the RSI $=500 \mathrm{msec}$ than in the RSI $=1,500 \mathrm{msec}$ condition, because larger association patterns are formed in the former condition; and it is higher when the available capacity is artificially reduced, as is the case under dual-task conditions.

\section{EXPERIMENT 3}

The main goal of Experiment 3 was to replicate the correlational pattern obtained in Experiment 2 in two independent samples that differed in age. A secondary, exploratory goal was to learn whether age-related differences in short-term memory capacity would affect the degree of implicit learning. D. V. Howard and J. H. Howard $(1989,1992)$ have recently found that the degree of implicit serial learning in a single-task version of the Nissen and Bullemer task does not differ between young adults (college-aged subjects) and elderly adults. However, elderly adults typically exhibit a reliably lower shortterm memory capacity than young adults do (see, e.g., Botwinick \& Storandt, 1974; Kausler, 1991; Light \& Anderson, 1985; Salthouse, 1991). Thus, given the empirical finding of Experiment 2, one might expect to find agerelated differences in implicit serial learning under dualtask conditions.

The basic setup of Experiment 3 was identical to that of Experiment 2, except that the RSI manipulation was dropped. Instead, RSI was set to $200 \mathrm{msec}$ for all subjects. Only task load (single vs. dual task) was experimentally manipulated, and the effects of the manipulation were observed in both a young adult sample and an elderly adult sample of subjects.

\section{Method}

Subjects. The subjects were 55 young ( 18 male, 37 female) and 54 elderly ( 19 male, 35 female) adults. The young adults were undergraduate students at the University of Missouri, Columbia, who received course credit for participating. The elderly adults were recruited from the Columbia, Missouri, area from a list of university faculty and staff retirees and their spouses, from local retirement homes, and from respondents to newspaper advertisements.

Materials and Procedure. The stimuli used in Experiment 3 were identical to those used in Experiment 2, except that subjects in Experiment 3 also responded to several survey questions prior to participation in the experimental task. These questions concerned the subjects' age, self-reported health status (recorded on a 1 [excellent] to 5 [very poor] Likert-type scale), and years of education. The experimental procedure was identical to the one used in Experiment 2 , except that the RSI manipulation was dropped (RSI = $200 \mathrm{msec}$ was used instead for all subjects) and the digit span task was administered auditorily, rather than visually. Because some elderly subjects had complained about the length of the experiment in pilot testing, the digit span measure was the only measure of short-term memory capacity employed.

\section{Results}

After eliminating data from subjects who did not perform the tone-counting task adequately in the dual-task 
conditions, using the same procedure as that described for Experiment $2(N=6$ in the young adults sample and $N=5$ in the elderly adults sample), there remained 16 subjects in the single-task-young condition, 16 subjects in the single-task-elderly condition, 33 subjects in the dual-task-young condition, and 33 subjects in the dualtask-elderly condition.

Descriptive information. The descriptive information for the two age groups is displayed in Table 5. The age group difference in health status was not reliable $[F(1,96)$ $\left.=3.42, M S_{\mathrm{e}}=0.76, p>.07\right]$. Both the age group difference in years of education $\left[F(1,96)=30.04, M S_{\mathrm{e}}=\right.$ $8.59, p<.0001]$ and the age group difference in digit span performance $\left[F(1,96)=5.45, M S_{\mathrm{e}}=0.99, p<\right.$ $.05]$ were reliable.

Experimental task: Indirect measure of serial learning. As in the previous experiments, subjects made relatively few errors in the experimental task. Mean error rates ranged from $0.1 \%$ to $1.3 \%$ across conditions. Figure 5 presents the means of subject median RTs in the four experimental conditions over the 12 trial blocks. A 2 (task load: single vs. dual task) $\times 2$ (age group: young vs. elderly) $\times 8$ (trial block: 1-8) mixed-design ANOVA of RTs for the initial eight trial blocks revealed a reliable main effect of task load $\left[F(1,94)=43.32, M S_{c}=868,346\right.$, $p<.001]$. In addition, elderly subjects performed more slowly than younger subjects $\left[F(1,94)=51.18, M S_{\mathrm{e}}=\right.$ $868,346, p<.001]$. The main effect of trial block was also reliable $\left[F(7,658)=37.49, M S_{e}=20,919, p<.001\right]$. None of the interactions were reliable (all $p s>.12$ ).

Degree of learning in the four experimental conditions was quantified as the mean difference in RT between Trial Blocks 8 and 9 (RT8-RT9), as was done in Experiment 2. The mean difference scores were $101,96,39$, and $8 \mathrm{msec}$, for the single-task-young, single-task-elderly, dual-task-young, and dual-task-elderly conditions, respectively. A 2 (task load: single vs. dual task) $\times 2$ (age group: young vs. elderly) ANOVA of the difference scores yielded a reliable main effect of task load $[F(1,94)=$ $22.89, M S_{e}=6,476, p<.001$ ], but no reliable main effect of age group and no reliable interaction between task load and age group (both $p s>.13$ ).

Because the pattern of means seemed to indicate the presence of an interaction between age group and task load, and because the lack of significance for the interaction in the present ANOVA may have been due to differences in sample size in the single- and dual-task con-

Table 5

Descriptive Information for Subject Characteristics (Experiment 3)

\begin{tabular}{lcccc} 
& \multicolumn{2}{c}{ Young } & \multicolumn{2}{c}{ Elderly } \\
\cline { 2 - 5 } \multicolumn{1}{c}{ Variable } & $M$ & $S D$ & $M$ & $S D$ \\
\hline Age & 18.8 & 1.3 & 73.7 & 7.3 \\
Health status & 1.9 & 0.9 & 2.2 & 0.9 \\
Education & 13.3 & 2.2 & 16.6 & 3.5 \\
Digit span & 7.71 & 1.00 & 7.25 & 0.99 \\
\hline
\end{tabular}

Note-Health status was rated on a 1 (excellent) to 5 (very poor) Likerttype scale.

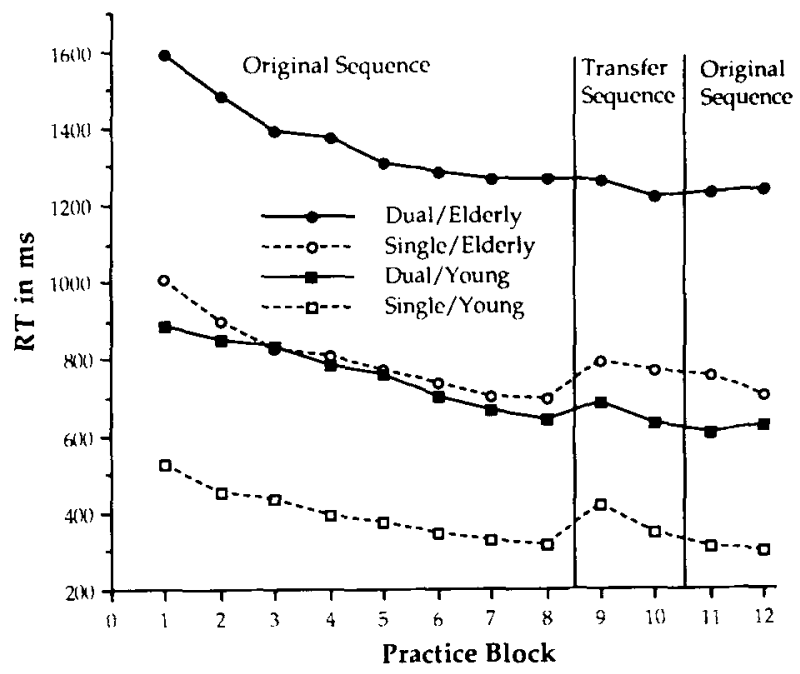

Figure 5. Mean response time as a function of age group, task load, and block of trials (Experiment 3).

ditions $(N=32$ in the single-task conditions vs. $N=66$ in the dual-task conditions), we ran separate ANOVAs of the single-task and dual-task conditions with age group as the only independent variable. In the single-task condition, the main effect of age group was not reliable $(F<1)$. In contrast, in the dual-task condition, the main effect of age group was reliable $\left[F(1,64)=6.21, M S_{\mathrm{e}}=\right.$ $5,670, p<.05]$. We therefore conclude, albeit somewhat cautiously in the absence of a reliable interaction between age group and task load, that age, at least for healthy adults, does not seem to affect implicit learning under single-task conditions, but that it does appear to affect implicit learning under dual-task conditions.

Free recall: Direct measure of serial learning. The free recall data are displayed in Table 3. As can be seen, young and elderly adults averaged exactly the same scores on the direct measure of learning in both the single-task and the dual-task conditions. Because the two age groups did not differ in their explicit recall of the repeating sequence, the age group difference on the implicit measure of learning under dual-task conditions did not appear to result from younger adults' being more aware of the repeating pattern.

Relation between memory span measures and indirect measure of serial learning. Across all experimental conditions, the mean digit span was $7.48(S D=1.02)$. Table 6 contains the correlations between the indirect, RT, measure of serial learning and digit span for the four experimental conditions. As can be seen, the correlations between digit span and the indirect measure of serial learning were, for both age groups, reliable in the dual-task situation, but not in the single-task situation. These results replicate the findings obtained in Experiments 1 and 2 , and they are consistent with the assumption that degree of implicit serial learning is related to short-term memory capacity. 
Table 6

Correlations Between Digit Span and Indirect Measure of Serial Learning as a Function of Experimental Condition (Experiment 3)

\begin{tabular}{lccc} 
Experimental & \multicolumn{3}{c}{ Age } \\
\cline { 2 - 4 } Condition & Young & Elderly & All \\
\hline Single task & 0.09 & 0.06 & 0.07 \\
Dual task & $-0.58 \dagger$ & $-0.31^{*}$ & $-0.44 \dagger$ \\
All & $-0.37 \dagger$ & -0.17 & \\
\hline
\end{tabular}

Note-Correlations are based on varying sample sizes. ${ }^{*} p<.05$. $\dagger p<.01 . \quad \ddagger p<.001$.

\section{Discussion}

The main purpose of Experiment 3 was to replicate the correlational pattern observed in Experiment 2. The replication was clearly successful in both age samples. Shortterm memory capacity correlated reliably with the indirect measure of learning under dual-task, but not under singletask, conditions.

A secondary goal of Experiment 3 was to compare the degree of implicit learning in an elderly adult and a collegeaged sample. We had hypothesized that age differences in implicit serial learning would be larger under dual-task conditions than under single-task conditions, because of age-related differences in short-term memory capacity. The dual-task results were consistent with this prediction and are also consistent with previous findings regarding implicit memory deficits in the elderly (see, e.g., Chiarello \& Hoyer, 1988; Light \& Burke, 1988; Rose, Yesavage, Hill, \& Bower, 1986; Wright \& Payne, 1985).

As with any age comparison, however, this conclusion is tempered by the fact that the young and elderly samples likely differed on several variables that might have produced the difference in implicit learning under dualtask conditions. First, one might argue that there are substantial age differences in baseline (i.e., Block 1) RTs, raising the question of whether it is appropriate to use absolute difference scores as the measure of implicit learning. Had we used a proportional measure (e.g., absolute difference divided by initial, Block 1, RT), for example, the age difference under dual-task conditions would have been much less pronounced. We did not use a proportional measure, however, because (1) it would have required the unjustified assumption that all component processes (i.e., peripheral input-output processes and central processes) underlying implicit serial learning are equally affected by age, which they are clearly not (see Arenberg, 1982; Salthouse, 1985); (2) the use of difference scores to assess implicit learning is in keeping with earlier research that has compared groups differing in baseline response times (e.g., D. V. Howard \& J. H. Howard, 1989, 1992; Knopman \& Nissen, 1987; Nissen \& Bullemer, 1987, Experiment 4; Nissen et al., 1987); and (3) differences in baseline RTs did not appear to affect the degree of implicit serial learning, as assessed by the difference measure, in the single-task conditions (see Figure 5).

Other variables that might have produced or contributed to the present age effect are, for example, age-related dif- ferences in attentional capacity (see, e.g., Plude \& Hoyer, 1985) and in cognitive slowing (see, e.g., Salthouse, 1985, 1991). In addition, one could argue that spatial capacities are reduced in elderly subjects, for which the subjects might compensate by devoting more attentional resources. Therefore, the age-related deficit in implicit learning shows up only when attention to the primary task is diminished by a secondary task. ${ }^{5}$ Clearly then, in the absence of appropriate measures of spatial ability, attentional capacity, and cognitive speed, the present results should be treated with caution. To the extent that it is possible to develop measures of these variables that are also independent of measures of short-term memory capacity, future research will need to address the individual contributions of all of these variables to age-related differences in implicit serial learning.

\section{GENERAL DISCUSSION}

The main goal of the present experiments was to examine the relation between an indirect measure of serial learning and two aspects of short-term memory: shortterm memory capacity and the activation level of the tobe-learned information. Together, the experiments show that the activation level, operationalized as rate of presentation, affects RT-based measures of implicit learning in such a way that lower activation levels (i.e., slower presentation rates) lead to decreased levels of implicit learning. Short-term memory capacity, as measured by traditional span measures, is also related to degree of implicit learning, but only when the capacity limit has been reached, as is the case under intentional instruction conditions or when a secondary task must be performed concurrently with the primary task. These findings are consistent with the predictions of the framework described in the introduction.

\section{Are the Effects of Activation Level and Short-Term Memory Capacity Independent?}

Within our theoretical framework, it is assumed that the effects of activation level and short-term memory capacity on the degree of implicit learning are independent of each other. Capacity refers to the amount of long-term memory information that can be activated at any time and is assumed to be relatively constant across time. Level of activation, in contrast, refers to the current activation level of individual nodes in long-term memory that have been activated. Individual activation levels are assumed to decay rather rapidly over time.

It could be argued that individual differences in capacity limitations arise only as a result of individual differences in activation level (i.e., decay rate). For example, the digit span difference observed between young and elderly adult samples could be explained by assuming that younger subjects have higher levels of activation for the to-be-recalled information, due perhaps to an increased rate of rehearsal (e.g., Baddeley, 1986). If, indeed, capacity is completely determined by the level of activation, it would not be sur- 
prising that both variables demonstrated effects on implicit learning in the present set of experiments.

Although theoretically plausible, such an interpretation, we believe, would not be entirely consistent with the present findings, because presentation rate and capacity measures show dissociable effects on implicit learning. In Experiment 1, for example, presentation rate affected learning under both intentional and incidental task instructions, whereas capacity effects were found only for the intentional $/$ RSI $=500 \mathrm{msec}$ condition. Similarly, presentation rate affected learning in both the single-task and the dual-task condition in Experiment 2, but capacity effects were observed only for the dual task/RSI = 500 msec condition. Thus, it appears that the effects of presentation rate and capacity are, at least to some extent, empirically separable.

\section{Short-Term Memory Capacity and Degree of Implicit Learning}

In the present experiments, reliable correlations between the span measures and degree of implicit learning were obtained only when RSI was $500 \mathrm{msec}$ and when task instructions were intentional (Experiment 1) or when a dualtask (Experiments 2 and 3) situation was realized. To explain this finding, we have argued that capacity affects implicit learning only when the capacity limit is reached. That is, when RSI $=500 \mathrm{msec}$, learned patterns are presumably larger than when RSI $=1,500 \mathrm{msec}$, and larger patterns are more likely to reach the capacity limit than smaller patterns. Therefore, capacity effects are most obvious when task instructions are intentional-that is, when subjects actively try to form large patterns, or when shortterm memory capacity is artificially reduced by a secondary task.

For this explanation to be correct, it is crucial to demonstrate that subjects can indeed learn patterns that are large enough to reach their short-term memory capacity limit. Some existing evidence suggests that subjects can indeed form patterns consisting of six or more stimuli. Remington (1969), for instance, showed that subjects' responses in a two-choice reaction time task were affected by elements as removed as five steps. Similarly, studies by Millward and Reber $(1968,1972)$ demonstrated sensitivity to as much as seven preceding elements in a twochoice probability learning paradigm. More recently, both Lewicki et al. (1987) and Stadler (1989) showed that subjects can form patterns of length six or seven in a task in which the location of the target on the seventh trial was determined by the locations of the targets on the six previous trials.

However, it does appear that the likelihood of learning patterns decreases with increasing pattern length (Cleeremans \& McClelland, 1991). For example, the differences in response probabilities between structured and unstructured events observed by Millward and Reber (1972) decreased with increasing length of the stimulus patterns and were very small for the longest patterns ( .52 vs. .47 for structured vs. unstructured events at pattern length seven).
As Cleeremans and McClelland (1991) have noted, a sensible explanation for this and similar findings is to assume "that memory for sequential material is limited and that the traces of individual sequence elements decay with time"' (p. 250). Such an assumption is indeed at the heart of the theoretical framework that we have presented, and it is also an important part of early models of sequence processing (e.g., that of Laming, 1969). Moreover, such an assumption is consistent with Servan-Schreiber and Anderson's (1990) recent model of learning in the artificial grammar task, in which it is assumed that learning is based on automatic, memory-based mechanisms that detect patterns of similarity among stored memory traces (see also Jacoby \& Brooks, 1984).

However, as Cleeremans and McClelland (1991) also argue, the finding that longer patterns are less likely to be formed than short patterns does not necessarily require the assumption of a decay mechanism. In fact, in Cleeremans and McClelland's own connectionist theory that models performance in both an artificial grammar learning task and the Nissen and Bullemer task (see also Jordan, 1986; Jordan \& Rumelhart, 1992), such a finding is explained without reference to a decay mechanism. Instead, according to Cleeremans and McClelland, the model forms stimulus patterns that become increasingly more similar to each other as the lengths of the patterns increase. The fact that longer patterns are learned less well than shorter patterns is due to the model's increasing difficulty in choosing among very similar stimulus configurations, rather than to the effects of a decay mechanism.

Although the Cleeremans and McClelland (1991) model offers a reasonable alternative to the assumption of a decay mechanism, the present findings suggest that at least part of the reason why short patterns are more likely to be learned than long patterns may be decay. Notice that in the present Experiments 1 and 2, learning in the RSI = $500 \mathrm{msec}$ and RSI $=1,500 \mathrm{msec}$ conditions should have been exactly identical if Cleeremans and McClelland's assumption is correct. Indeed, the authors' model appears to predict that RSI should not have an effect on implicit learning, a prediction inconsistent with other findings in the literature as well (see, e.g., Frensch et al., in press). Thus, in its present form, the Cleeremans and McClelland model does not appear to be capable of accounting for the results presented in this article.

\section{Implicit Learning and Implicit Memory}

The theoretical framework for implicit learning that was described in the introduction can, at least in principle, be extended to cover implicit memory phenomena as well. That is, within the framework, implicit memory effects (see, e.g., Richardson-Klavehn \& Bjork, 1988; Roediger, 1990; Schacter, 1987) are due to the activation of longterm memory information outside the focus of attention. In contrast, implicit learning may be seen as resulting from the implicit processing of information that was activated either inside or outside of the focus of attention. Thus, this rather simple framework predicts that there should 
be some variables that affect both implicit learning and memory similarly, and that there should be other variables that affect implicit learning and memory differently. For example, because it is assumed that implicit learning can only operate on activated long-term memory information, any variable that affects the process of activation should affect implicit memory and implicit learning similarly (e.g., familiarity, changes in physical features of information). On the other hand, variables that alter the effectiveness of the associative learning mechanism (e.g., type of covariation) may not necessarily affect implicit memory.

\section{REFERENCES}

ARENBERG, D. (1982). Learning from our mistakes in aging research. Experimental Aging Research, 8, 73-76.

Baddeley, A. D. (1986). Working memory. Oxford: Oxford University Press, Clarendon Press.

Baddeley, A. D. (1992). Working memory. Science, 255, 556-559.

BerRy, D. C., \& BroadBent, D. E. (1984). On the relationship between task performance and associated verbalizable knowledge. Quarterly Journal of Experimental Psychology, 36A, 209-231.

BerRY, D. C., \& BroAdBENT, D. E. (1988). Interactive tasks and the implicit-explicit distinction. British Journal of Psychology, 79, 251-272.

Berry, D. C., \& Dienes, Z. (1991). The relationship between implicit memory and implicit learning. British Journal of Psychology, 82 , 359-373.

Botwinick, J., \& STORANDT, M. (1974). Memory, related functions and age. Springfield, IL: Charles C. Thomas.

Broadbent, D. E. (1984). The Maltese cross: A new simplistic model for memory. Behavioural \& Brain Sciences, 7, 55-94.

Chinarllo, C. , Hoyer, W. J. (1988). Adult age differences in implicit and explicit memory: Time course and encoding effects. Psychology \& Aging, 3, 358-366.

Cleeremans, A., \& MCClelland, J. L. (1991). Leaming the structure of event sequences. Journal of Experimental Psychology: General, 120, 235-253.

CoHEN, A., IVRY, R. I., \& KEELE, S. W. (1990). Attention and structure in sequence learning. Joumal of Experimental Psychology: Leaming, Memory, \& Cognition, 16, 17-30.

CowaN, N. (1988). Evolving conceptions of memory storage, selective attention, and their mutual constraints within the human information-processing system. Psychological Bulletin, 104, 163-191.

CowaN, N. (1993). Activation, attention, and short-term memory. Memory \& Cognition, 21, 162-167.

Curran, T., Ke Kele, S. W. (1993). Attentional and nonattentional forms of sequence learning. Journal of Experimental Psychology: Learning, Memory, \& Cognition, 19, 189-202.

Dienes, Z. (1992). Connectionist and memory-array models of artificial grammar learning. Cognitive Science, 16, 41-79.

Estes, W. K. (1976). The cognitive side of probability learning. Psychological Review, 83, 37-64.

Estes, W. K. (1986). Memory storage and retrieval processes in category learning. Journal of Experimental Psychology: General, 115, 155-174.

Falmagne, J. C. (1965). Stochastic models for choice reaction time with application to experimental results. Journal of Mathematical Psychology, 2, 77-124.

Fendrich, D. M., Healy, A. F., \& Bourne, L. E. (1991). Long-term repetition effects for motoric and perceptual procedures. Joumal of Experimental Psychology: Learning, Memory, \& Cognition, 17, 137-151.

FrensCh, P. A. (1991). Transfer of composed knowledge in a multistep serial task. Joumal of Experimental Psychology: Learning, Memory, \& Cognition, 17, 997-1016.

Frensch, P. A. (in press). Composition during serial learning: A serial position effect. Journal of Experimental Psychology: Learning, Memory, \& Cognition.
Frensch, P. A., Buchner, A., \& Lin, J. (in press). Implicit learning of unique and ambiguous serial transitions in the presence and absence of a distractor task. Journal of Experimental Psychology: Learning, Memory, \& Cognition.

Frensch, P. A., \& GEARY, D. C. (1993). The effects of practice on component processes in complex mental addition. Journal of Experimental Psychology: Leaming, Memory, \& Cognition, 19, 433-456.

GoschKE, T. (1992, April). The role of attention in implicit learning of structured event sequences. Paper presented at the Annual Conference for Experimental Psychologists, Osnabrück, Germany.

HaRTMan, M., KNOPMan, D. S., \& Nissen, M. J. (1989). Implicit learning of new verbal associations. Journal of Experimental Psychology: Learning, Memory, \& Cognition, 15, 1070-1082.

Hayes, N. A., \& BRoADbENT, D. E. (1988). Two modes of learning for interactive tasks. Cognition, 28, 249-276.

HEBB, D. O. (1949). The organization of behavior: A neuropsychological theory. New York: Wiley.

HEBB, D. O. (1961). Distinctive features of learning in the higher animal. In A. Fessard, R. W. Gerard, J. Konorsky, \& J. F. Delafresnaye (Eds.), Brain mechanisms and learning (pp. 37-51). Oxford: Blackwell.

Hintzman, D. L. (1990). Human learning and memory: Connections and dissociations. Annual Review of Psychology, 41, 109-139.

Howard, D. V., \& HowARD, J. H., JR. (1989). Age differences in learning serial patterns: Direct versus indirect measures. Psychology \& Aging, 4, 357-364.

HowarD, D. V., \& Howard, J. H., JR. (1992). Adult age differences in the rate of learning serial patterns: Evidence from direct and indirect tests. Psychology \& Aging, 7, 232-241.

Howard, J. H., JR., MutTer, S. A., \& Howard, D. V. (1992). Serial pattern learning by event observation. Journal of Experimental Psychology: Leaming, Memory, \& Cognition, 18, 1029-1039.

JACOBY, L. L., \& BROOKS, L. R. (1984). Nonanalytic cognition: Memory, perception, and concept learning. In G. Bower (Ed.), The psychology of learning and motivation: Vol. 18 (pp. 1-47). New York: Academic Press.

JACOBY, L. L., Toth, J. P., \& Yonelinas, A. P. (1993). Separating conscious and unconscious influences of memory: Measuring recollection. Journal of Experimental Psychology: General, 122, 139-154.

JoRDAN, M. I. (1986). Attractor dynamics and parallelism in a connectionist sequential machine. In Eighth Annual Conference of the Cognitive Science Society (pp. 531-546). Hillsdale, NJ: Erlbaum.

Jordan, M. I. , \& Rumelhart, D. E. (1992). Forward models: Supervised learning with a distal teacher. Cognitive Science, 16, 307-354.

KAUSLER, D. H. (1991). Experimental psychology, cognition, and human aging. New York: Springer-Verlag.

KEELE, S. W., \& JENNINGS, P. J. (1992). Attention in the representation of sequence: Experiment and theory. Human Movement Science, 11, 125-138.

KeELe, S. W., \& Summers, J. G. (1976). Structure of motor programs. In G. E. Stelmach (Ed.), Motor control: Issues and trends (pp. 109 142). New York: Academic Press.

KNOPMAN, D. S. (1991). Unaware learning versus preserved learning in pharmacological amnesia: Similarities and differences. Journal of Experimental Psychology: Leaming, Memory, \& Cognition, 17, 1017-1029.

KNOPMAN, D. S., \& Nissen, M. J. (1987). Implicit learning in patients with probable Alzheimer's disease. Neurology, 37, 784-788.

LAMING, D. R. J. (1969). Subjective probability in choice-reaction experiments. Journal of Mathematical Psychology, 6, 81-120.

Lewickı, P., Czyzewska, M., \& Hoffman, H. (1987). Unconscious acquisition of complex procedural knowledge. Joumal of Experimental Psychology: Learning, Memory, \& Cognition, 13, 523-530.

LEwICKı, P., Hill, T., B Bizot, E. (1988). Acquisition of procedural knowledge about a pattern of stimuli that cannot be articulated. Cognitive Psychology, 20, 24-37.

Light, L. L., \& ANDERSON, P. A. (1985). Working-memory capacity, age, and memory for discourse. Journal of Gerontology, 40, 737-747.

LigHT, L. L., \& BURKE, D. M. (1988). Patterns of language and memory in old age. In L. Light \& D. Burke (Eds.), Language, memory, and aging (pp. 244-271). Cambridge: Cambridge University Press.

Lin, J., Frensch, P. A., \& Buchner, A. (1993). Implicit serial learning in the presence and absence of a distractor task. Manuscript in preparation. 
Mathews, R. C., Buss, R. R., Stanley, W. B., Blanchard-Fields, F., Cho, J. R., Druhan, B. (1989). Role of implicit and explicit processes in learning from examples: A synergistic effect. Journal of Experimental Psychology: Learning, Memory, \& Cognition, 15, $1083-1100$.

McKelvie, S. J. (1987). Learning and awareness in the Hebb digits task. Journal of General Psychology, 114, 75-88.

Millward, R. B., \& ReBer, A. S. (1968). Event recall in probability learning. Journal of Verbal Learning \& Verbal Behavior, 7, 980-989.

Millward, R. B., \& Reber, A. S. (1972). Probability learning: Contingent-event schedules with lags. American Journal of Psychology, 85, 81-98.

MYERS, J. L. (1979). Fundamentals of experimental design. Boston: Allyn \& Bacon.

Nelson, D. L., Schreiber, T. A., \& McEvoy, C. L. (1992). Processing implicit and explicit representations. Psychological Review, 99, 322-348.

Nissen, M. J., \&ullemer, P. (1987). Attentional requirements of learning: Evidence from performance measures. Cognitive Psychology, 19, 1-32.

NisSen, M. J., Knopman, D. S., \& Schacter, D. L. (1987). Neurochemical dissociation of memory systems. Neurology, 3, 789-793.

Nissen, M. J., Willingham, D. B., \& Hartman, M. (1989). Explicit and implicit remembering: When is learning preserved in amnesia? Neuropsychologia, 27, 341-352.

Perruchet, P., Amorim, M.-A. (1992). Conscious knowledge and changes in performance in sequence learning: Evidence against dissociation. Joumal of Experimental Psychology: Learning, Memory, \& Cognition, 18, 785-800.

Plude, D. J., HoYeR, W. J. (1985). Attention and performance: Identifying and localizing age deficits. In N. Chamess (Ed.), Aging and human performance (pp. 47-100). New York: Wiley.

REBER, A. S. (1967). Implicit learning of artificial grammars. Journal of Verbal Learning \& Verbal Behavior, 6, 855-863.

REBER, A. S. (1989). Implicit learning and tacit knowledge. Journal of Experimental Psychology: General, 118, 219-235.

REMINGTON, R. J. (1969). Analysis of sequential effects in choice reaction times. Journal of Experimental Psychology, 82, 250-257.

Richardson-Klavehn, A., \& BJork, R. A. (1988). Measures of memory. Annual Review of Psychology, 39, 475-543.

ROEDIGER, H. L., III (1990). Implicit memory: Retention without awareness. American Psychologist, 45, 1043-1056.

Rose, T. L., Yesavage, J. A., Hill, R. D., \& Bower, G. H. (1986). Priming effects and recognition memory in young and elderly adults. Experimental Aging Research, 12, 31-37.

SAlthouse, T. A. (1985). A theory of cognitive aging. Amsterdam: North-Holland.

SALthouse, T. A. (1991). Mediation of adult age differences in cognition by reductions in working memory and speed of processing. Psychological Science, 2, 179-183.

SCHACTER, D. L. (1987). Implicit memory: History and current status. Joumal of Experimental Psychology: Leaming, Memory, \& Cognition, $13,501-518$.

SerVAN-Schreiber, E., \& ANDERSON, J. R. (1990). Learning artificial grammars with competitive chunking. Journal of Experimental Psychology: Learning, Memory, \& Cognition, 16, 592-608.

StAdLER, M. A. (1989). On learning complex procedural knowledge.
Journal of Experimental Psychology: Learning, Memory, \& Cognition, 15, $1061-1069$.

STADLeR, M. A. (1992). Statistical structure and implicit serial learning. Journal of Experimental Psychology: Learning, Memory, \& Cognition, 18, 318-327.

Willingham, D. B., Nissen, M. J., \& Bullemer, P. (1989). On the development of procedural knowledge. Journal of Experimental Psychology: Learning, Memory, \& Cognition, 15, 1047-1060.

WINER, B. J. (1971). Statistical principles in experimental design (2nd ed.). New York: McGraw-Hill.

Wright, B. M., PAYNe, R. B. (1985). Effects of aging on sex differences in psychomotor reminiscence and tracking proficiency. Journal of Gerontology, 40, 179-184.

\section{NOTES}

1. The use of the terms implicit and explicit serial learning has not always been consistent in the literature. In this article, we use implicit and explicit to refer to the hypothetical learning processes underlying task performance in serial tasks. In addition, we use the terms incidental and intentional to refer to whether or not instructions established a learning task for subjects, and the terms direct and indirect to describe the type of measure applied to assess learning.

2. Notice that our framework, as well as Cowan's (1988) model, assumes a unitary short-term memory that includes different types of knowledge. In contrast, Baddeley $(1986,1992)$ has argued that shortterm memory consists of two separate types of memory, a phonological loop and a visuospatial sketchpad. Because the Nissen and Bullemer (1987) task is primarily a spatial task, one would, following Baddeley, expect that only the capacity of the visuospatial sketchpad, but not the capacity of the phonological loop, should correlate with implicit learning in the Nissen and Bullemer task. By utilizing two different capacity measures, we were able to determine the short-term memory capacity for phonological (digit span) as well as spatial (location span) information. As it turned out, the correlational patterns were highly similar for the two memory span measures. These results are consistent with the theoretical framework described in the introduction.

3. In most studies of the Nissen and Bullemer (1987) task that have used the generate task in the past, subjects were not told to reproduce a prior sequence, but rather were simply asked to guess where the asterisk would appear next. As Perruchet and Amorim (1992) pointed out recently, the lack of information on the relation between study and test phases in those experiments classified the generate task as an indirect, rather than direct, memory test (Richardson-Klavehn \& Bjork, 1988). 4. The variances of the difference scores were $1,996 \mathrm{msec}$ and $987 \mathrm{msec}$ in the intentional and incidental conditions, respectively $[F(33,34)=2.02, p<.05]$. The relatively large variance in the intentional condition appeared to have been caused by a few subjects with relative small effects (i.e., RT difference between Blocks 8 and 9) among many subjects with relative large effects. The wide range of the magnitude of the effects in the intentional condition may reflect a variety of different approaches or strategies that subjects bring to bear on the task (e.g., different hypothesis-testing approaches).

5 . We thank Daniel Willingham for this suggestion.

(Manuscript received January 6, 1993; revision accepted for publication June 23,1993 .) 